\title{
Information transfer by local field potentials in the hippocampal formation
}

\author{
Maria Constantinou*, Daniel Squirrell, John Gigg, Marcelo A Montemurro \\ From 24th Annual Computational Neuroscience Meeting: CNS*2015 \\ Prague, Czech Republic. 18-23 July 2015
}

Extracellular electrical potential oscillations recorded as local field potentials (LFPs) in the hippocampal formation are thought to be involved in cognitive processes such as working memory retention, memory consolidation and spatial navigation. Recent studies have shown that combining spikes with LFP phase can increase the information content of spikes $[1,2]$ and thus suggest LFP oscillations have the capacity to convey information. LFP oscillations within specific frequency bands can interact, for example by phase-phase and phase-amplitude coupling. We hypothesise that these LFP interactions can transfer information between neural networks. To test this hypothesis, we analyse multi-channel recordings of simultaneous LFPs from hippocampal area CA1 and the subiculum of urethane-anaesthetised rodents. Anatomical connections between these two regions in the hippocampal formation predict information in this system flows in 'nested loops' along separate projections [3]. We use advanced neurocomputational methods to determine how information flows within the CA1-subicular circuit by interactions of LFP rhythms. The results of correlation and coherence analyses of LFPs recorded from multiple sites suggest that LFP rhythms can transmit information within and between area CA1 and the subiculum. However, these methods alone are not enough to determine the oscillatory activity in which region drives activity in other regions, that is in which direction information flows. We use transfer entropy [4], which is an information theoretic method that can capture directionality, to quantify information transfer between area CA1 and subiculum. We show that information flow within the CA1-subicular circuit is bi-directional and follows a pattern of feedforward and feedback loops. Our results suggest that LFP interactions can route information at millisecond

\footnotetext{
* Correspondence: maria.constantinou@manchester.ac.uk Faculty of Life Sciences, University of Manchester, Manchester, M13 9PT, UK
}

timescales along the anatomical connections in the hippocampal formation to achieve cognitive processing.

Published: 18 December 2015

\section{References}

1. Montemurro MA, Rasch MJ, Murayama Y, Logothetis NK, Panzeri S: Phaseof-firing coding of natural visual stimuli in primary visual cortex. Curr Biol 2008, 18(5):375-380.

2. Kayser C, Montemurro MA, Logothetis NK, Panzeri S: Spike-phase coding boosts and stabilizes information carried by spatial and temporal spike patterns. Neuron 2009, 61(4):597-608.

3. Gigg J: Constraints on hippocampal processing imposed by the connectivity between CA1, subiculum and subicular targets. Behav Brain Res 2006, 174(2):265-271.

4. Schreiber T: Measuring information transfer. Phys Rev Lett 2000, 85(2):461-464.

\section{doi:10.1186/1471-2202-16-S1-P168}

Cite this article as: Constantinou et al:: Information transfer by local field potentials in the hippocampal formation. BMC Neuroscience 2015 16(Suppl 1):P168.

\section{Submit your next manuscript to BioMed Central and take full advantage of: \\ - Convenient online submission \\ - Thorough peer review \\ - No space constraints or color figure charges \\ - Immediate publication on acceptance \\ - Inclusion in PubMed, CAS, Scopus and Google Scholar \\ - Research which is freely available for redistribution

() Biomed Central 